Marquette University

e-Publications@Marquette

Economics Faculty Research and Publications

Economics, Department of

$1-1-1998$

New Keynesians, Post Keynesians and History

John B. Davis

Marquette University, john.davis@marquette.edu

Published version."New Keynesians, Post Keynesians and History", in New Keynesian Economics / Post Keynesian Alternatives. Ed. Roy Rotheim. New York: Routledge, 1998. 168-181. Publisher Link. (C) 1998 Taylor and Francis (Routledge). Used with permission. 


\title{
NEW KEYNESIANS, POST KEYNESIANS AND HISTORY
}

\author{
John B. Davis
}

The New Keynesian research programme possesses a number of features which are not unattractive to Post Keynesians. New Keynesians reject policy ineffectiveness, laissez-faire New Classical economics, and argue that the economy can lock into underemployment equilibria. New Keynesians allow for asymmetric information, imperfect competition, adjustment costs, externalities, strategic complementarity and increasing returns, and in some instances emphasize institutions and conventions. Yet New Keynesianism also possesses features Post Keynesians are generally critical of, including the standard subjective probability framework, rational expectations, the ISLM model, an insistence on microfoundations for macroeconomics, a reliance on traditional optimizing behavioural analysis, and little interest in Keynes's own thinking. In contrast, Post Keynesians emphasize true uncertainty regarding the future, reject rational expectations, regard the ISLM model as artificial and static, call for macrofoundations for microeconomics, argue for richer accounts of individual economic behaviour, and draw often on Keynes's own thinking.

Among these differences, Post Keynesians' emphasis on true uncertainty regarding the future has been central. Thus an interesting issue is whether there is also a related and equally strong dividing line between Post Keynesians and New Keynesians regarding the influence the past and our ignorance of it has on the present. Were both uncertainty about the future and ignorance about the past to distinguish Post Keynesianism from New Keynesianism, this might then point towards important differences between the two research programmes in regard to their respective views of the nature of economic behaviour. Recently Cross (1993) has suggested that there need not be important disagreements over the influence of the past by arguing that Post Keynesians might find the concept of hysteresis amenable to their understanding of the economic process. Hysteresis concerns phenomena that display a persistence of effects beyond the occasion of their initial causes. 'They may be thought characteristically historical in that the presence of such effects violates the standard presumption that physical systems are reversible. Indeed Post Keynesians have long used notions that apply irreversibility characteristics. 'Their analysis of fixed capital investment as fundamentally illiquid treats long-lived capital assets as firm- or at best industry-specific, and thus as rarely remarketed without significant 
NEW KEYNESIANS, POST KEYNESIANS AND HISTORY

loss. Their analysis of money contracts focuses on the relation between current and future money flows and financial obligations determined by past decisions.

Katzner (1993) has replied, however, that hysteresis as specifically understood by Cross and other contributors to the literature relies on systems of periodic equations that presuppose logical time and perfect knowledge, and that an analysis of the economy in terms of true historical time understood as unidirectional and irreversible better captures a Post Keynesian understanding of an economic process in time. ${ }^{1}$ Because 'reality is overwhelmingly complicated', our perceptions of the past 'are fraught with errors and gaps', implying that 'successive moments in historical time bring with them their own unique institutional and analytical structures' (p. 340). In effect, 'history is created period by period' (p. 343), and ignorance about the past plays directly into our uncertainty about the future. Indeed, ignorance about the past and uncertainty about the future are but two species of a knowledge about the world whose limitations tule out using subjective probability theory as an analytical device for economics.

Keynes clearly believed uncertainty about the future was central to our understanding of the economy. But how did he understand the effect of the past on the present, and did he believe that the economy moved in historical time in the sense of being created period by period? In an effort to develop the foundations for Post Keynesianism in terms of Keynes's own thinking, Kregel (1976) distinguished three alternative models used by Keynes in The General Theory and in his 1937 lectures in connection with differing assumptions about the nature and interaction of shortperiod and long-period price expectations. Dutt (1991-2) has argued, however, that only one of these three models is compatible with an account of the economy in which history might be said to matter in determining the direction and development of the economy. This chapter makes use of Dutt's path-dependency model of Keynes's thinking to produce - if not an account of an economy moving in true historical time - none the less an account in which the past can be seen to have a pattern of determinate effects on later time periods. The purpose in doing so is to begin to uncover the sorts of behavioural phenomena such an analysis implies phenomena which would receive fuller investigation in a genuinely historical analysis of the economy. The main assumption underlying the chapter is that the most important dividing line between Post Keynesianism and New Keynesianism concerns the degrees of realism in their respective understandings of individual behaviour. New Keynesians are strongly attached to formal, rational choice models, whereas Post Keynesians' concern with time, ignorance and uncertainty requires abandonment of static optimizing behavioural analysis and attention to decision making in concrete, historical circumstances. To sharpen this point, then, the chapter builds onto Dutt's path-dependency analysis of Keynes's thinking a Post Keynesian account of individual economic behaviour in terms of recent findings from the psychological literature on economic behaviour critical of rationality theory.

In the first section below, Dutt's discussion of Kregel's three models in Keynes is briefly reviewed to isolate the properties of Keynes's shifting equilibrium model 


\section{THE LABOUR MARKE'T}

that favour an account of the economy as path-dependent. In the section second, recent experimental evidence on the psychology of individual decision making consistent with there being a role for history in the economy is briefly summarized. In the third section, I supply an interpretation of Keynes's thinking in relation to this recent evidence about decision making that makes use of his own emphasis on the role conventions play in the economy. The final section draws conclusions about the heuristics of Keynes's models and the differences between New Keyncsianism and Post Keynesianism.

\section{STATIC, STATIONARY AND SHIFTING EQUILIBRIUM MODELS}

Kregel calls the model in which individuals' long-period price expectations, $E$, are constant and short-period price expectations $e$ are realized Keynes's static model, the model in which $E$ is constant but $e$ may be disappointed and changing Keynes's stationary model, and the model in which $E$ is shifting and $e$ may be disappointed Keynes's shifting equilibrium model. Only in the last, as the idea of shifting equilibrium suggests, are $e$ and $E$ interdependent. The static model appears only in Keynes's 1937 lectures, where it can be argued that in response to his critics and possible misunderstanding Keynes simplified his arguments from The General Theory to hammer home the single point that 'the theory of effective demand is substantially the same if we assume that short-period expectations are always fulfilled' (Keynes, 1973, p. 181). This suggests that he found the stationary model tactically inopportune, since obviously he knew short-period expectations were regularly disappointed, and thus that the static and stationary models were together a conceptualization alternative to the shifting equilibrium model. It also seems fair to say that Keynes principally used the stationary/static model when he thought a simplified exposition of his underemployment analysis required temporatily putting aside interdependence between $e$ and $E$. The shifting equilibrium model described how the economy moved from one underemployment equilibrium to another, and might consequently only be appreciated once economists were disabused of their Say's Law commitments.

Does the shifting equilibrium model capture the idea of an economy in historical time? Dutt argues that how seriously we take the equilibrium method generally in Keynes's thinking depends upon the relative weight placed on two different purposes for which the method can be used: 'to examine some qualitative property of the equilibrium position, and... to attach some real-world significance to the precise position of that equilibrium' (1991-2, pp. 218-19). Keynes's main purpose clearly - given that reigning classical theory presupposed the equilibrium method was to show that unemployment equilibria were possible, and, thus, to exhibit this particular qualitative property of equilibria obtained. From the perspective of this goal, 'Issues regarding the path-dependence of equilibrium, and the role of history, were no concern of his: wherever the economy ended up, it was possible for it to end with unemployed labor' (ibid., P. 219). But, Dutt adds, this focus is compatible 


\section{NEW KEYNESIANS, POST KEYNESIANS AND HISTORY}

with also arguing that the economy was path-dependent, nor would doing so undermine Keynes's main goal in qualitative analysis. ${ }^{2}$ And that Keynes also developed the shifting equilibrium model in The General Theory gives good reason to think this other goal was important to him also.

It is reasonable to ask, then, how the shifting equilibrium model may be thought to approximate an analysis of the economy in historical time. Suppose first, Dutt suggests, that the interdependence between $e$ and $E$ in the model arises from assuming that disappointed short-period expectations ${ }^{3}$ reasonably cause firms to alter their long-period expectations, so that $E=E(e)$ and $E^{\prime}>0$, as firms extrapolate the near future into the distant future. This results in three possibilities. ${ }^{4}$ First, a unique stable equilibrium may indeed exist (provided short-period expectations adjust adaptively), should we assume that the relationship between $E$ and $e$ reflects only current expectations. Here history does not matter. Second, the shortperiod equilibrium may also be unstable (when investment is highly responsive to changes in long-period expectations, and long-period expectations are highly responsive to changes in short-period expectations). Here equilibrium does not matter. Third, under certain circumstances pertaining to the relationship between $e$ and the price of output, there may also be multiple equilibria, where whether stable short-period equilibria are achieved depends upon the economy's starting-point. Here history matters.

Can the first case, then, be said to be Keynes's? Dutt's analysis is meant to show that a necessary condition for the economy to possess a unique stable equilibrium not dependent upon the economy's starting point and independent of the economy's dynamic path is that current levels of $E$ depend on current levels of $e$. But clearly it is not very plausible to say that current disappointed short-period price expectations alone determine current long-period price expectations. Firms undoubtedly also consider past realized and unrealized short-period expectations in formulating long-period expectations, and accordingly Dutt recommends that $E$ be thought also to depend upon lagged values of $e$. Thus suppose that $E_{t}=S^{T} k_{\mathrm{t}-\mathrm{i}} e_{\mathrm{t}-\mathrm{i}}$, the $k_{j}$ are weights and $T$ is the length of the firm's memory. Then the final equilibrium is path-dependent in that the final level of $E$ will depend upon the path by which $e$ adjusts, and history matters in determining the position of the economy in equilibrium. Dutt notes that this path-dependence depends upon the asymmetry in his analysis between how expectations are formed when short-period expectations are realized and how they are formed when they are not. He interprets this to mean that memory plays a role for firms when short-period expectations are disappointed, but has no role when they are realized (because then $e$ and $E$ cease to be interdependent). More specifically, firms remember their mistakes, and act to change what they regard as mistakes, but see no reason to change what they are doing when their expectations are fulfilled.

This is surely a reasonable thing to say about the psychology of decision making in firms and indeed with respect to human behaviour generally. But whether we should regard Keynes's shifting equilibrium model as one that makes history matter in this way, and indeed whether Post Keynesians should give weight to Keynes's 


\section{THE LABOUR MARKET}

shifting equilibrium model or develop alternative modes of historical analysis requires further argument. I address the first of these issues in the next two sections of this chapter by, first, looking at some recent experimental evidence concerning the psychology of individual decision making to see what general sorts of phenomena might underlie a memory that emphasizes mistakes and errors, and by, second, then turning to an account of Keynes's thinking about conventions in the economy that draws on similar considerations. Comment on the latter issue of how Post Keynesians should look upon the shifting equilibrium model in addressing the nature of time is reserved for the concluding section.

\section{THE PLACE OF ERROR IN MEMORY: RECENT EVIDENCE FROM EMPIRICAL PSYCHOLOGY}

Here I only attempt to draw attention to a small portion of the empirical literature from psychologists that has attracted the interest of economists increasingly sceptical in recent years of the adequacy of the traditional axiomatization of rational choice. Of course economists have had doubts of this sort since the early work of Simon (1957) on bounded rationality and Allais' (1952) thought experiments (see Allais and Hagen, 1979) challenging the independence axiom of expected utility theory, but it has only been in the last decade and a half that confidence in the a priori deductive method of explaining choice seems to have begun to be seriously shaken (e.g. Sugden, 1991). Three phenomena are described here: loss aversion, preference reversals, and time-inconsistent preferences. In each case, $I$ argue that the phenomenon in question might contribute to an account of individual behaviour in which a memory of mistakes has a role in influencing expectations of the future.

\section{Loss aversion}

Kahneman and Tversky (1984) have drawn attention to an asymmetry in ascriptions of value they term loss aversion, whereby individuals feel that the disutility involved in giving up an object exceeds the utility associated with acquiring it. Loss aversion may be understood to imply that individuals' evaluation of risky outcomes tends to reflect a status quo bias, so that there may well be important irreversibilities in our preferences. Recall that the standard theory of rational choice assumes that indifference curves are reversible in the sense that an individual regarding two bundles of goods as equally valuable should be indifferent between having one and trading it for the other and having the second and trading it for the first. Having a status quo bias or being loss averse means that this may often not be the case, and that in certain circumstances indifference curves may even cross one another (cf. Knetsch, 1990). Individuals faced with objects of equal value in their own view thus tend to prefer those objects that they already possess, even when this violation of the transitivity axiom implies that they may be irrational in the specific sense of being a potential money pump. ${ }^{5}$ 
That preferences may often be irreversible clearly raises serious questions about the adequacy and generality of the standard theory of rational choice that assumes individuals possess stable and unchanging preference orders. Tversky and Kahneman (1991) have thus developed an alternative preference theory that explains how indifference curves may be indexed to reference levels that count as status quo factors for individuals. One advantage of such an approach is that it improves on rational choice models ignoring individuals' status quo bias that generally predict 'greater instability than is observed in the world' (Samuelson and Zeckhauser, 1988). Another advantage of their approach is that its emphasis upon irteversibilities in individuals' evaluation of risky outcomes serves to place important emphasis upon how choice may be embedded in historical time as opposed to logical time. That individuals tend to exhibit status quo bias might be understood to reflect their concern with an uncertain future (in regard to both states of nature and the qualities of goods), and thus count as an effective demonstration of the idea that the conditions needed to apply subjective probability theory to the world do not always hold.

What is the implication of loss aversion and status quo bias for Keynes's shifting equilibrium model interpreted as a path-dependent analysis? On the argument that we disproportionately remember our mistakes, fulfilled short-period expectations might be regarded as choices that involve no departure from the status quo and no mistakes, i.e. as status-quo-preserving choices. In contrast, when short-period expectations are not realized, they might be seen as mistakes about which the firm felt a special aversion. On this view, one should not confuse mistakes associated with loss aversion with business or personal losses per se, since clearly some of a firm's mistakes may be associated with expectations that are, as it were, overfulfilled, as when a firm's price and sales are better than expected. From the perspective of how short-period expectations influence long-period expectations, that the former are under-or over-fulfilled would always have some impact on the latter. Loss aversion, then, is more a matter of how a relatively settled state of affairs, as manifest in a set of short-period expectations, is disturbed, either unfavourably or favourably. From the point of view of human psychology, individuals are thus more comfortable with modest or no change whatsoever in their environment when faced with the task of evaluating risky future prospects.

\section{Preference reversals}

One of the best-known psychological results that challenges standard rational choice theory concerns preference reversals. First demonstrated by Lichtenstein and Slovic $(1971,1973)$, and then replicated by many others, preference reversals occur when individuals are asked, first, to choose between two gambles of nearly the same expected value (one with a high chance of winning a small prize and one a low chance of winning a large prize), and, second, to price each of those gambles. Most subjects choose the high-chance-small-prize gamble, but then put a higher price on the low-chance-high-prize gamble, thus exhibiting what has come to be 
known as preference reversal. Interestingly, Grether and Plott designed a set of experiments explicitly meant 'to discredit the psychologists' work as applied to economics' (1979, p. 623), but found themselves unable to do so. They concluded that 'no optimisation principles of any sort lie behind the simplest of human choices and that the uniformities in human choice behaviour which lie behind market behaviour may result from principles which are of a completely different sort than generally accepted' (ibid.).

Subsequent research has focused on explaining the various possible causes of preference reversals. Some have thus supposed that preference reversals involved intransitive preferences, and proposed non-transitive preference choice models to address the problem (e.g. Loomes and Sudgen, 1983). Other researchers questioned the formulation of payoff schemes in such a manner as to test the independence axiom of expected utility theory (e.g. Karni and Safra, 1987). Finally, a third set of researchers tested procedure invariance or whether alternative ways of presenting a choice always give rise to the same ordering (Slovic et al., 1990). The latter argued that intransitivities and payoff schemes explained only a relatively small share of preference reversals, while a failure of procedure invariance accounts for a large portion of preference reversals. They also argued that procedure invariance breakdowns could be seen to be related to the compatibility of stimulus and response for experimental subjects involved in decisions involving both choice and pricing, reasoning that individuals grasp some stimuli more readily than others.

How is this research relevant to Keynes and the issue of path-dependency? The failure of procedure invariance implies that different ways of presenting a choice to individuals change the way in which they order the options before them. In the view of Slovic et al. (ibid.), it suggests that individuals may not have stable and unchanging preferences which are elicited in one situation after another, and that preference is (at least in part) context dependent. Such a state of affairs would be just what one would expect if the economic process occurred in historical rather logical time. Indeed it would be consistent with Katzner's view that 'history is created period by period', when there are 'steady alterations in the epistemic statuses and decision opportunities of individuals as they learn of and experience new things' (1993, p. 343). It would also be consistent with memory of mistakes possessing an important role in choice if mistakes in short-period expectations were to transform the opportunities firms faced. If unrealized expectations, as contrasted to realized ones, were to alter 'the epistemic statuses and decision opportunities of individuals', then firms might exhibit preference reversals and the economy then behave in a path-dependent manner.

\section{Time-inconsistent preferences}

Another well-established anomaly from the perspective of rational choice theory is the phenomenon of time-inconsistent preferences associated with intertemporal choice. It has long been recognized that individuals may well exhibit negative, declining and variable time discount rates, as opposed to the constant rates that 


\section{NEW KEYNESIANS, POST KEYNESIANS AND HISTORY}

standard theory predicts. Strotz (1955) thus demonstrated that dynamic inconsistencies in behaviour of the sort involving discount rates that decline over time imply that individuals consume more in the future than their earlier plans had permitted. Elster (1979) argued that individuals who revise their earlier consumption plans gone awry with the passage of time ought to be said to reflect a second-best rationality. A number of researchers have looked upon intertemporal choice as a manifestation of internal conflict between an individual's multiple selves, bringing up Arrow-type difficulties for intrapersonal as compared to interpersonal collective choice (Thaler and Shefrin, 1981; Schelling, 1984).

Psychologists have termed any tendency to favour the present over the future myopia. Its extent can depend upon a variety of factors including how choices are framed for individuals and whether they look upon future benefits or costs with favour or dread. In connection with the framing idea, it has been shown that individuals react differently to relative money amount differences and absolute money amount differences (Lowenstein and Prelec, 1989). Benzion et al. (1989) have shown that individuals discount time differently according to how far off a gain or loss lies in the future. Lowenstein (1987) showed that the maximum payments individuals would make to obtain or avoid various future outcomes also varied according to the perceived pleasantness or unpleasantness of the outcome. More generally, individuals appear to react differently to the prospects of gains as compared to losses in the future. These and other similar results suggest intertemporal choice involves additional complications to our understanding of complexities of choice at a point in time.

Intertemporal choice inconsistencies, however, are especially relevant to an investigation of how history might matter in the economy. If individuals systematically mis-estimate gains and losses at different points in the future, and often then find themselves in a position of wanting to revise their past choices, then they not only make mistakes regularly, but just as regularly make adjustments in their situations to accommodate those mistakes. Long-period expectations on this view would be sensitive to lagged values of short-period expectations in that firms would likely come to recognize general patterns of short-period expectation failure. Specifically, if errors regarding future values are a persistent feature of decision making, firms would be unable to correct for their future mistakes in advance, and would find it their best - or more accurately second-best - strategy to put themselves in a position regularly to discover and adjust to past mistakes. The economy would then be path-dependent in the sense that in each period decision makers would find themselves in the position of having to discover new phenomena that could not previously have been anticipated.

\section{KEYNES AND CONVENTION}

Might Keynes have allowed that such psychological phenomena as loss aversion, preference reversals, and time-inconsistent preferences may play a role in the development of the economy over time? Though traditional choice-theoretic 


\section{THE LABOUR MARKET}

reasoning underlies parts of The General Theory, Keynes also drew attention to the animal spirits of entrepreneurs as that 'spontaneous urge to action rather than inaction' (1973a, p. 161), and thus clearly did not believe that individuals always behaved as constrained maximizers. In addition, many of Keynes's other writings on history and policy, such as The Economic Consequences of the Peace, demonstrate insight into the psychological complexities of character and personality, and it thus seems not unrealistic to suppose that Keynes developed his understanding of the behaviour of entrepreneurs and speculators alongside his understanding of politicians, Treasury officials and artists. In any event, here I put aside what Keynes might himself have thought, and suppose that there is enough in the overall framework of The General Theory to allow that a history of mistakes made in forming short-period expectations possesses a role in determining long-period expectations. On this analysis, Keynes's shifting equilibrium model can be understood to treat the economy as if it were path-dependent, and to do so on account of the sorts of psychological characteristics of individual decision making that have been the subject of recent interest in the empirical literature on rational choice.

To flesh out this argument I turn to a subject on which Keynes appears to have been most alive to a richer account of behaviour and individual reasoning: that is, his thinking about the role of conventions in the economy, specifically in connection with firms' investment decisions. My strategy is to look at how Keynes thought conventions acted as a framework for individual decision making that might have enabled individuals to adjust to the sorts of psychological anomalies discussed above. We know that Keynes thought that individuals relied upon conventions when uncertainty about the future and presumably ignorance about the past limit rationality. But just how do conventions play this role in this decision making? More to the point, what specific difficulties in decision making do the special characteristics Keynes attributed to conventions permit individuals to address? On the argument here, since psychological anomalies of the sort described in the recent literature arise specifically in atomistic reasoning contexts, it is the atomistic nature of rational choice reasoning that conventions may be said to address and counter-balance. Conventions thus assist individual decision making by providing an interactionist framework for choice in comparison with what atomistic rational choice theory assumes.

First, then, how did Keynes understand conventions? I have argued elsewhere (Davis, 1994) that Keynes's philosophical development led him to take conventions to be (dynamic) structures of interdependent individual expectations. ${ }^{6}$ Conventions, that is, are not habits of mind, rules of thumb, or customary practices that an individual might elect to consult, but rather modes of interaction between individuals all forming judgements on related matters. This comes out most cleatly in Keynes's treatment of investment in The General Theory, in which the convention 'that the existing state of affairs will continue indefinitely, except in so far as we have specific reason to expect a change' $(1973 \mathrm{a}, \mathrm{p}, 156)$ is analysed in terms of the interplay between average expectation and individual expectation regarding the value of any given investment. Average expectation is redetermined daily as 


\section{NEW KEYNESIANS, POST KEYNESIANS AND HISTORY}

individual investors bid and offer equity issues at various prices. Individual expectations adjust daily in response to the changing average expectation of the market recorded as end-of-the-day values. Thus the 'existing state of affairs' regarding any set of investment prospects 'will continue indefinitely' as long as the average expectation regarding those investments remains relatively settled; that is, until a large enough number of individual investors 'have specific reason to expect a change' in the value of those investments.

This interaction that conventions tend to structure between individuals, in Keynes's treatment of both investment and money markets, has been recognized by many readers of The General Theory. Less often emphasized, however, has been what makes the interaction Keynes describes an interaction in which individuals are also interdependent with one another in the very process of decision making. To see this difference, we may make a distinction between an individual reacting to the choices others make, as, say, reflected in market outcomes, and an individual reacting to the thinking others are thought to employ in making their choices. Keynes emphasizes that when individual investors try to outguess the market or 'outwit the crowd' (p. 155) they actually try to anticipate the thinking of other investors. They are not content, that is, to act only on the basis of how others actually invest, but also attempt to construe how others reach their conclusions about how, when and why to invest, in order then to be in a position to form an 'opinion of what average opinion expects average opinion to be' (p. 156). ${ }^{7}$

The sort of reasoning that an attention to the thinking of others requires differs in one important respect from what is typically assumed about the reasoning process of economic agents. Whereas traditional rational choice analysis supposes individuals only make use of their own preferences, to form judgements about the thinking of others one needs to be able to see things from their point of view, or attempt to grasp the nature of their preferences. One needs, in effect, to place oneself in the shoes of one's competitors. Reasoning of this sort may be termed analogical in that it involves individuals working out their own thoughts by using the thinking of other individuals they suppose to be like themselves and in similar circumstances as reference points. It represents a significant departure from traditional atomistic decision making in which inference from tastes and circumstances to choice is assumed to be strictly autonomous, Robinson Crusoe style, in that it allows individuals may determine or 'complete' their own preferences by imagining those of others. Of course in Keynes's view, investors and speculators were not a collection of independent Robinson Crusoes, since when the opinions of the crowd mattered more than the underlying essentials of an investment, individual investors were likely to cobble together patterns of inference for themselves out of what appeared to be successful intuitions and insights on the part of others. The passing of the age of enterprise with the separation of ownership and management thus produced a new form of reasoning in the speculative practices of modern investment markets, and this gave conventions as structures of interdependent decision making a central role in the operation of the economy. 


\section{THE LABOUR MARKET}

Generally, then, the reason why one would wish to think conventions were important in economies with significant uncertainty about the future and ignorance about the past is straightforward. When rationality is limited in these ways, one obvious and available means of attempting to enhance one's decision-making capacity is to survey and make use of the reasoning of others who are similarly constrained. Keynes's treatment of time and uncertainty can thus be said to presuppose the proposition that atomistic individual rationality is not just bounded but also inadequate as an account of the interdependent decision-making process in which individuals actually engage. But how does this general conclusion apply to the psychological phenomena above that have been of recent interest in the literature on choice anomalies? I have already suggested that loss aversion, preference reversals, and time-inconsistent preferences could be associated with circumstances in which individuals' long-period expectations are influenced by their mistakes in forming short-period expectations. What remains to be done is to say how these sorts of phenomena might play a role in Keynes's shifting equilibrium model by saying how these problems in atomistic individual rationality were the sorts of problems Keynes thought conventions addressed. More specifically, what remains to be done is to show that loss inversion, preference reversals and time-inconsistent preferences produce in individuals a recourse to the sort of analogical thinking that conventions as structures of truly interdependent expectations make possible.

\section{Loss aversion and conventions}

In the case of loss aversion, we saw that individuals tend to exhibit a status quo bias in their evaluation of risky prospects, and that this implied the existence of important irreversibilities in taste and intransitive preferences. Tversky and Kahneman (1991) built upon this evidence in developing an alternative preference theory in which indifference curves are indexed to reference levels that constitute status quo factors for individuals. If we interpret this in terms of how a history of mistakes regarding short-period expectations influences the formation of longperiod expectations, then the economy may be said to be path dependent in part because of the phenomenon of loss aversion. If we now add to this account Keynes's thinking about conventions as structures of interdependent expectations, it can be argued that the reference levels Tversky and Kahneman conceptualize correspond to average expectations regarding firm pricing success and investment values across markets. Investors form their individual expectations with the most recent evidence from the market in mind. Their uncertainty about the future impels them to investigate whether past short-period expectations have been fulfilled, and to incorporate this information in forming their long-period expectations. They do this by considering others' views about short-period performance and the prospects for various investments. Individual expectations are then interdependent and dependent upon a complex system of reference points comprising measures of different market's average performance and individuals' various assessments of that average performance. If we take the formation of long-period expectations to 
NEW KEYNESIANS, POST KEYNESIANS AND HISTORY

reflect attention to unfulfilled short-period expectations in this way, Keynes's understanding of conventions as structures of interdependence can be thought to make the loss aversion and status quo bias analysis of Kahneman and Tversky a part of the story of an economy's path dependency.

\section{Preference reversals and conventions}

We saw that preference reversals arise when individuals prefer one of a pair of risky gambles, but place a higher price on the other. We also saw that though one set of researchers has attributed preference reversals to intransitive preferences and another has attributed them to problems in the formulation of payoff schemes (and expected utility theory's independence axiom), a case can be made for saying that most preference reversals derive from breakdowns in procedure invariance, where at issue is the compatibility for individuals of stimulus and possible response. For Slovic et al. (1990), this opens up the possibility that, contrary to traditional rationality theory, preferences may not be stable and unchanging, but rather are often formed in specific contexts. Such a view would be consistent with what Keynes's suggestions regarding analogical reasoning and conventions would allow about how individuals constitute their own reasoning processes. When speculators borrow inferences and thinking from rivals and colleagues, their preferences are indirectly influenced by other's preferences, so that, to the extent that individuals have their own preferences, interdependent judgement guarantees that those preferences are always in a state of development. Then, as Katzner says, history could be thought to develop 'period-by-period', in that steady alteration in the terms on which interdependent individuals reason about their current and past experience would transform the opportunities they faced in an uncertain future.

\section{Time-inconsistent preferences and conventions}

Time-inconsistent preferences are associated with perverse discount rates and the phenomenon of individuals revising their consumption plans as the future becomes the present. The myopia psychologists see this reflecting is often interpreted to be the product of various cognitive framing effects, where, for example, individuals tend to assess future prospects differently according to whether they look upon them with favour or dread. An interesting contribution to this literature on the part of economists concerns multiple selves analysis. They argue that just as there are a variety of interpersonal collective choice problems, so there may also be said to be a variety of parallel intrapersonal collective choice problems in which the single individual is seen to possess multiple utility functions. Such an analysis, it seems, is not much removed from what Keynes believes to be involved in conventions as structures of interdependent judgement. Thus to the extent that investors try to anticipate 'what average opinion expects average opinion to be' (1973a, p. 156), they effectively acquire multiple selves whose opinions compete with one another in such a manner that the voice that periodically emerges as uppermost for the 


\section{THE LABOUR MARKET}

individual investor is often enough later seen as ill-advised and myopic. Certainly time-inconsistent preferences and perverse discount rates are no stranger to speculation. Long-period expectation formation here too, then, might be said to be the product of past patterns of unfulfilled short-period expectations.

\section{CONCLUDING REMARKS}

Keynes has generally been understood to have placed considerable emphasis upon demonstrating that an economy in equilibrium could have unemployment. Indeed his attention to the static model version of his theory in his post-General Theory writings is commonly taken as a tactic for communicating with readers strongly wedded to equilibrium thinking. This hardly implies, however, that he thought the economy was not path-dependent or that history did not matter to the development of the economy. Indeed, a case can be made for just such a view based on Dutt's interpretation of Keynes's shifting equilibrium model. It should be noted, then, that the discussion here is not meant to imply that, given a longer life, Keynes would have built upon an interaction between short-period and long-period expectations in the manner of this chapter to utilize the sort of recent psychological evidence regarding individual behaviour the chapter surveys. It is rather meant to show, first, that Keynes's understanding of conventions as structures of interdependent expectations reflects an understanding of human decision making that draws on themes similar in nature to those in recent empirical research in psychology, and, second, that this shared view of human decision making permits an account of the economy operating in historical time. From this perspective, it is suggested that Keynes's views about interactive decision making combined with recent empirical research in psychology provide foundations for a Post Keynesian account of individual economic behaviour in real time that is significantly different to that which New Keynesianism allows.

This last point deserves comment. Arguably one important reason why traditional, ISLM Keynesians have been unable to respond effectively to the New Classicals' attack on Keynesian thinking in recent years is that they accepted the neoclassical claim that macroeconomic thinking needs to be erected on a microfoundations base of atomistic rational choice theory. New Keynesian thinking in this respect represents not a return to Keynes, but rather an effort to supplement traditional Keynesian theory with rational expectations-rational choice foundations that are complicated by information asymmetries, strategic complementarity, imperfect competition, etc. Keynes, we might say, anticipated this kind of New Keynesian innovation with his own emphasis upon the limitations in human decision making and individuals' consequent recourse to conventional behaviour. Post Keynesians recognize this distinctive element in Keynes's views when they emphasize the importance of uncertainty about the future. The recommendation of this chapter is that Post Keynesians should further supplement this insight with an account of ignorance about the past and in terms of a general view of decision making in historical time. 


\section{NEW KEYNESIANS, POST KEYNESIANS AND HISTORY}

\section{ACKNOWLEDGEMENTS}

The author is indebted without implication to Amitava Duff, Tracy Mott, Steve Pressman, Roy Rotheim, Jochen Runde, and two anonymous readers for comments on an earlier version of this chapter.

\section{NOTES}

1 The debate originated in Davidson's assertion that 'hysteresis does not deal with the impact of those societal historical changes which create a true uncertainty environment for many economic decisions' (1991, p. 133). Davidson (1993) is a response to Cross's argument that hysteretic processes are non-ergodic.

2 Though it does rule out that technocratic fine-tuning of the economy by fiscal and monetary policy means is possible.

3 The analysis of disappointed short-period expectations is put in all-or-nothing terms to simplify the discussion. As one (anonymous) reader to the chapter pointed out, expectations normally comprehend a range of possible outcomes.

4 See Dutt (1991-2) for exposition of the model on which the following depends.

5 Were an individual's preferences intransitive $(a>b>c>a)$ and the individual willing to pay some amount to exchange a less preferred for a more preferred good, others could trade with this individual until 'pumping out' all of the individual's money or wealth.

6 See Littleboy (1990) for a general discussion of Keynes on convention.

7 Keynes allows that this sort of higher-order 'second' guessing may occur in many markets. 